\title{
The Lean Six Sigma Algorithm-A Pathway for Decreasing the Continuous Improvement Projects Failure Rate ${ }^{\dagger}$
}

\author{
Karam Al-Akel * and Liviu-Onoriu Marian \\ Faculty of Machine Building, Technical University of Cluj-Napoca, 400114 Cluj-Napoca, Romania; \\ liviu.marian@yahoo.com \\ * Correspondence: karam.alakel@gmail.com \\ + Presented at the 14th International Conference on Interdisciplinarity in Engineering-INTER-ENG 2020, \\ Târgu Mureș, Romania, 8-9 October 2020.
}

Published: 23 December 2020

\begin{abstract}
Even if Lean and Six Sigma tools are available for large audiences, many of the continuous improvement projects fail due to the lack of a pathway that ensures appropriate results in a timely manner. We would like to address this universal issue by generating, testing and validating an algorithm that improves manufacturing processes in a controlled manner. With a selection of the most valuable set of tools and concepts implemented in a specific order, a guideline for successful project implementation is proposed. Decreasing the overall number of continuous improvement project failures is the main scope of our algorithm and suggested methodology.
\end{abstract}

Keywords: lean manufacturing; Six Sigma; pharma industry; algorithm; roadmap; project structure; failure

\section{Introduction}

The continuous improvement of ongoing processes is a natural target for any company that aspires to maintain a competitive advantage on the market. Lean Six Sigma is one of the main methodologies preferred to be implemented with this scope and it maintains a continuous improvement culture and proper results [1]. Even if the Lean and Six Sigma tools are available for the larger public, many of the projects fail due to the lack of a pathway that ensures appropriate results in a timely manner [2,3]. We would like to address this universal issue by generating, testing and validating an algorithm that improves manufacturing processes in a controlled manner. As per our knowledge, an algorithm which addresses this general issue in such detail is not yet available. Decreasing the number of continuous improvement projects failures is the main scope of our algorithm.

\section{Theoretical Background}

Lean Six Sigma is a continuous improvement culture applied all across the world in several industries, with the deepest roots in automotive [4]. Even if the Lean principles have been available for over 30 years [5], many of the continuous improvement projects using its tools fail by missing a proper roadmap for applying them [1,2]. By starting to implement a project without the satisfaction of seeing its results in a timely manner, the project leaders will lose hope and motivation and will abandon the journey. Losing time and money without obtaining results is a no-go for any company. Lean Manufacturing and Six Sigma tools fusion has been proven to have beneficial effects in several companies and industrial fields [6-8]. Nevertheless, the missing link of a detailed implementation algorithm for the manufacturing area does not exist according to our knowledge. With high achievements reported 
across the world [9-14], the rate of Lean Six Sigma projects abandoned or failed is kept behind the curtains. Short-term goals and achievements are key aspects in change management and a successful continuous improvement project implementation [15].

\section{Materials and Methods}

In order to generate the proposed algorithm, several studies have been conducted to reveal the most used and efficient Lean Six Sigma tools across several global industries, and the obtained results have been embedded in the suggested structure $[16,17]$. According to analysis made in various fields, such as automotive, aeronautical, steel and pharmaceutical, a resemblance regarding the challenges faced in manufacturing areas defines four generic issues marked in the algorithm as $\mathrm{P} 1-\mathrm{P} 4$, with the assigned improvement projects: cycle time decrease (P1), changeover time reduction (P2), output increase (P3), defective parts decrease (P4). A pilot project has been conducted in the pharmaceutical industry in the original form of the algorithm to be able to adapt it to the needs and shop floor reality of the manufacturing area [18]. The lessons learned, key take-aways, best order and timing for the LSS tools' usage have been embedded in the final form of the algorithm [19-24].

The ultimate form of the generated algorithm, represented in Figure 1, has been implemented in the pharmaceutical industry, at a manufacturing site. The designated manufacturing line for applying the algorithm was the bottle packaging line for suspensions where the Overall Equipment Effectiveness (OEE, internally treated as OAE-Overall Asset Effectiveness) needed to be increased as customer demand has been forecasted to continue growing over time and capacity constraint has already been reached. The algorithm, represented in Figure 1, has been validated by positively affecting the OAE KPI (Key Performance Indicator) which includes several additional CTQs (Critical To Quality), such as weekly unplanned stoppages time, weekly planned stoppage time and weekly/monthly output. Under the umbrella of OAE, challenges regarding P1-P4 were proposed to be solved. An OAE increase of $10 \%$ from a baseline of $25 \%$ to the new value of $35 \%$ would increase productivity by over $30 \%$.

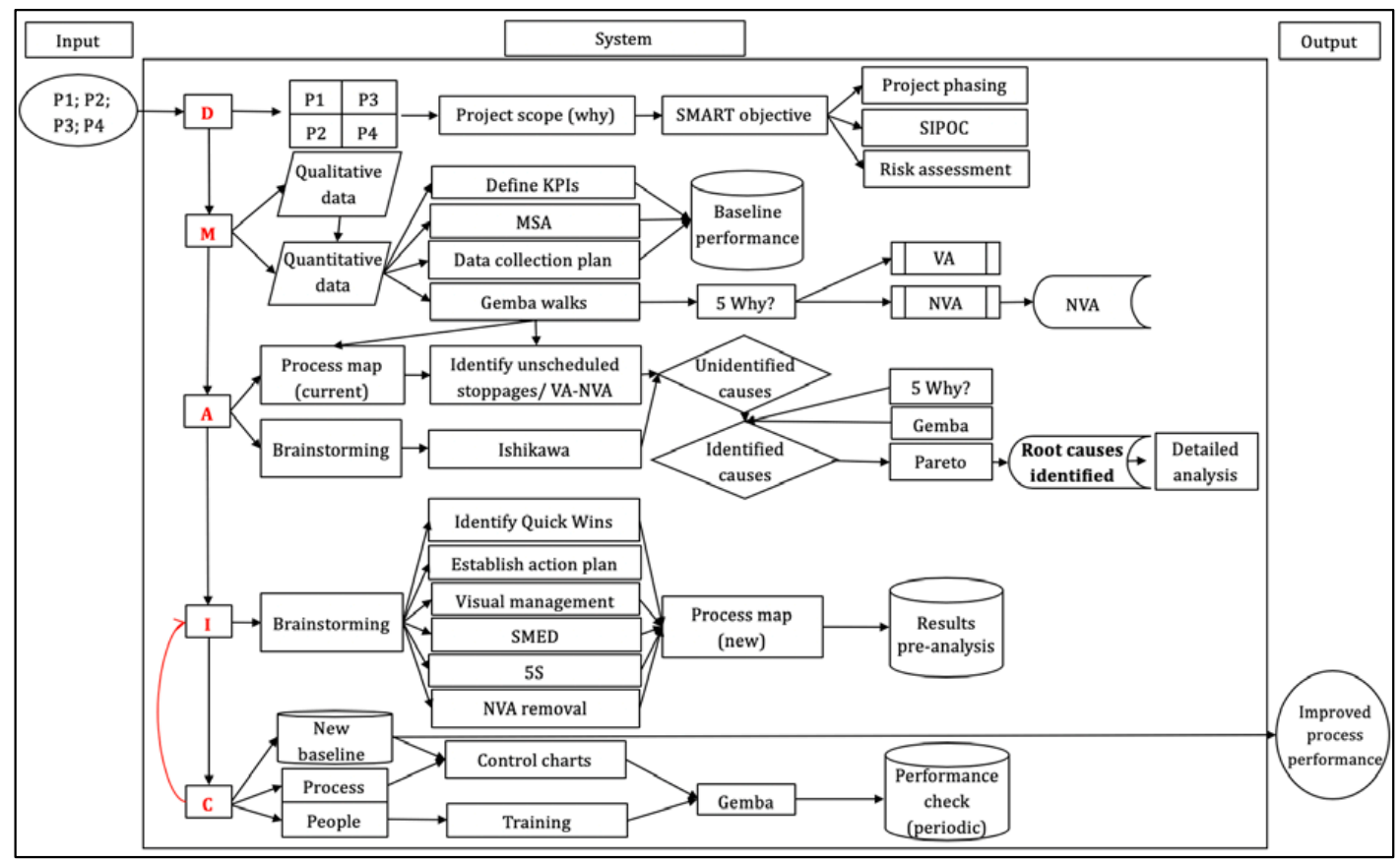

Figure 1. The Lean Six Sigma algorithm.

The main methodology for implementing the algorithm is revealed in a separate paper and states explicit examples of using the Lean Six Sigma tools and tips for applying them. The detailed results for the OAE components, such as planned and unplanned stoppage time, decrease, weekly output increases and waste (muda) removal results are presented in a related paper. 


\section{Results}

The Lean Six Sigma algorithm has been implemented for the presented project with a total analyzed timeframe of 18 months, out of which the core implementation period for most of the actions was six months. First, significant results could be noticed after a period of only two months from starting to implement the initial actions and discipline into the process. All the results have been obtained by following the algorithm.

With OAE being a complex KPI with several components, we tracked the daily, weekly and monthly performance, along with one of its components, on a weekly basis: changeovers, packaging line speed, unplanned stoppages, weekly output. As represented in Figure 2, OAE has been improved by $9 \%$ from $25 \%$ to a new baseline of $34 \%$.
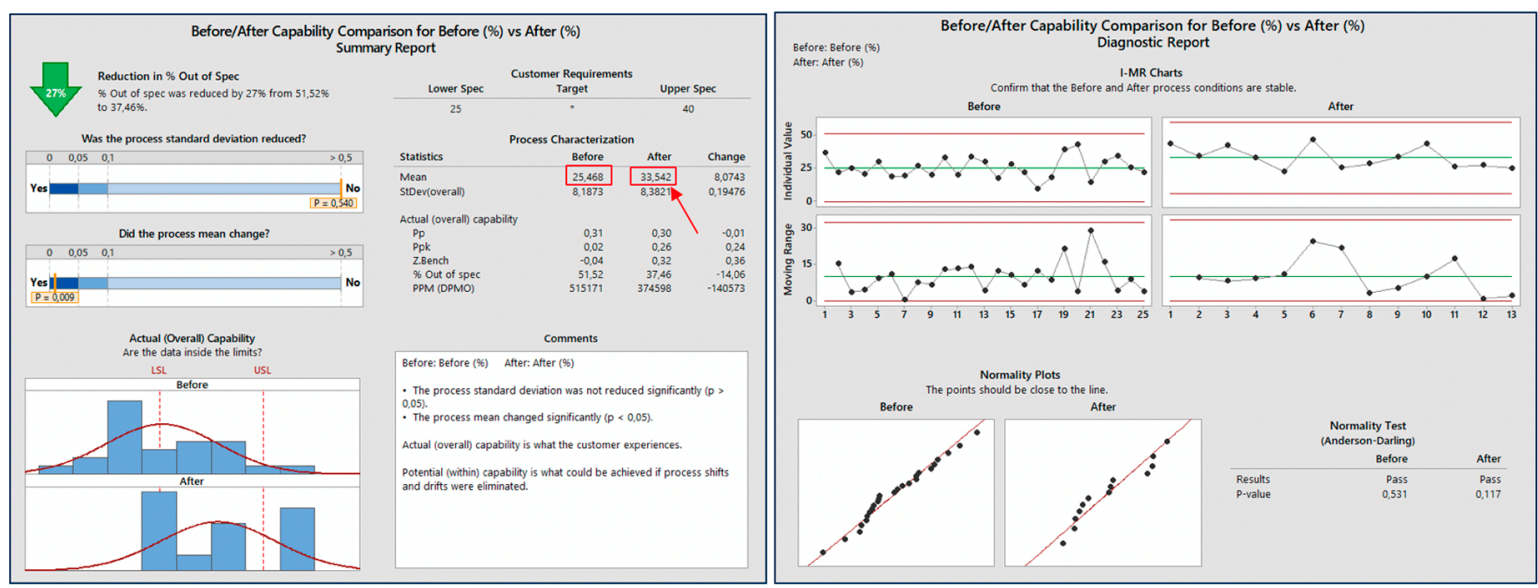

Figure 2. Overall Asset Effectiveness improvement.

The OAE Loss Tree presented in Figure 3 considers the losses from a time perspective, deliberately ignoring good count and asset net running speed. Nevertheless, both factors were included in the OAE calculation. We suggest targeting the OAE Loss Tree components as goals for smaller projects, and approaching them as a whole, in a structured manner according to the suggested algorithm, for the more complex ones.

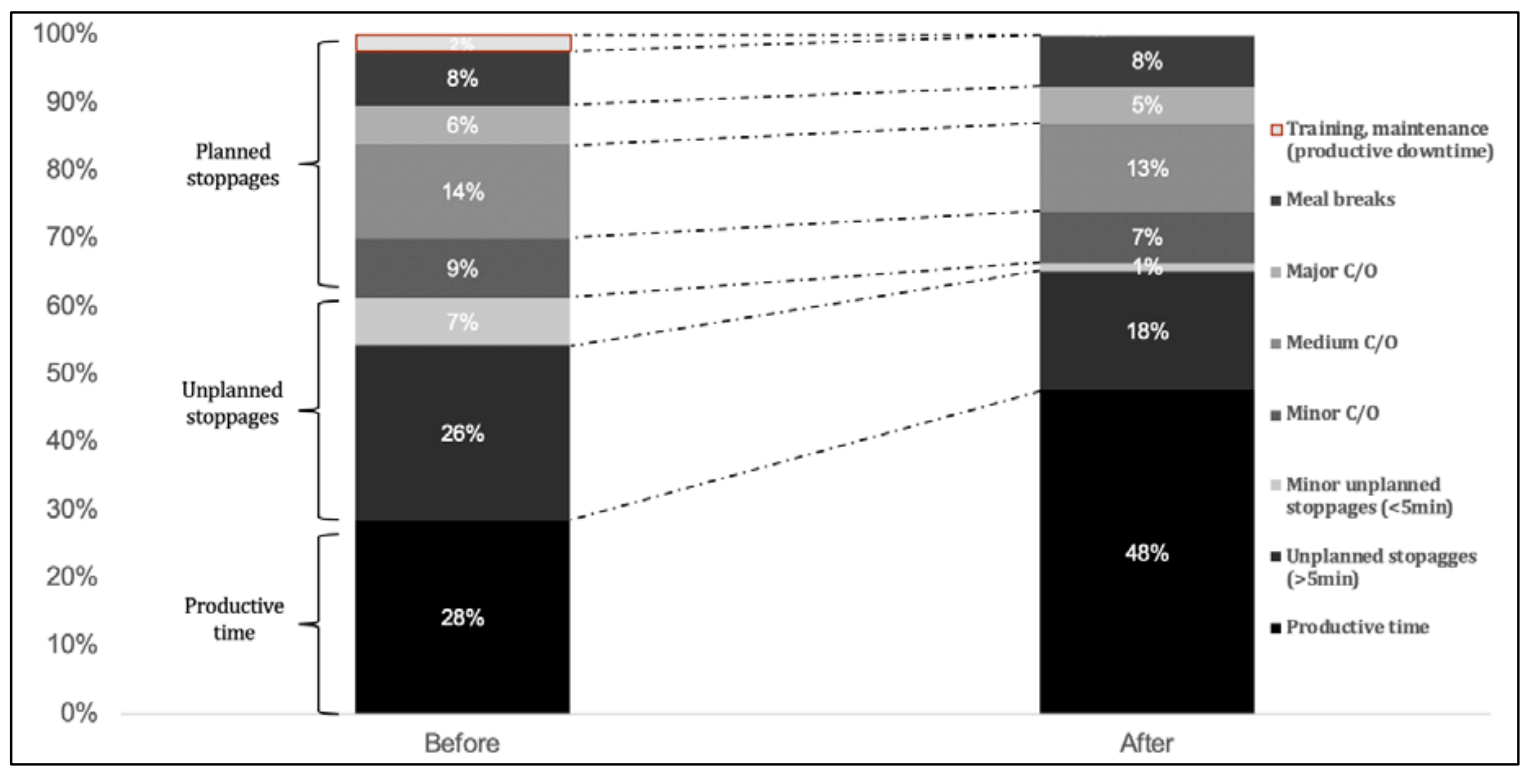

Figure 3. OAE Loss Tree. 


\section{Discussion}

The suggested Lean Six Sigma algorithm is structured on the standard DMAIC phases with the specific Lean Manufacturing and Six Sigma tools and suggestions for guidance, organized in the appropriate order for proper implementation. Following the Define, Measure, Analyze, Improve and Control project phases, the actions have been implemented in the manufacturing area of one pharmaceutical company. This current paper's purpose is not to offer specific details regarding the implementation of each tool used; those key aspects are covered in a separate material.

The main scope of the algorithm is decreasing the failure rate of the continuous improvement projects in the manufacturing areas. We addressed this universal issue by generating, testing and validating through results, an algorithm that improves the manufacturing processes in a controlled manner. The algorithm has been applied, tested and validated in the manufacturing area of a pharmaceutical company, yet conceived to enhance the improvement project's results in multiple batch manufacturing environments. Through improving the complex OAE KPI and its components, we consider the algorithm as a successful pathway in decreasing the failure rate of Lean Six Sigma continuous improvement projects. Through generating and testing a Lean Six Sigma algorithm for process improvement, using specific tools and techniques, we dispatch a validated roadmap for a general issue unaddressed in such detail until today.

Funding: This research received no external funding to be disclosed.

Acknowledgments: The paper would not have been created without the exceptional support of my guide and advisor, Liviu-Onoriu Marian. I would also like to express my deep gratitude to the company that allowed me to implement, test and validate the algorithm in the manufacturing area. I would like to thank the kind and knowledgeable support of the entire team who aided my efforts.

Conflicts of Interest: The funders had no role in the design of the study; in the collection, analyses, or interpretation of data; in the writing of the manuscript, or in the decision to publish the results.

\section{References}

1. Bhuiyan, N.; Baghel, A. An overview of continuous improvement: From the past to the present. Manag. Decis. 2005, 43, 761-771. [CrossRef]

2. Gerger, A.; Firuzan, A.R. Reasons of failure in Lean Six Sigma projects. Int. J. Multidiscip. Res. Dev. 2012, 2, 123-130.

3. Antony, J.; Lizarelli, F.L.; Fernandes, M.M.; Dempsey, M.; Brennan, A.; McFarlane, J. A Study into the Reasons for Process Improvement Project Failures: Results from a Pilot Survey. Int. J. Qual. Reliab. Manag. 2019, 36, 1699-1720. [CrossRef]

4. Womack, J.; Jones, D.; Roos, D. The Machine That Changed the World; MacMillan Publishing: New York, NY, USA, 1990.

5. Womack, J.; Jones, D. Lean Thinking; Simon and Schuster: New York, NY, USA, 1996.

6. Asli, Y.A.-B.; Jaideep, M.; Everett, M.S. When Lean and Six Sigma converge: A case study of a successful implementation of Lean Six Sigma at an aerospace company. Int. J. Technol. Manag. 2012, 57, 18-32.

7. Pepper, M.P.J.; Spedding, T.A. The evolution of lean Six Sigma. Int. J. Qual. Reliab. Manag. 2010, 27, $138-155$. [CrossRef]

8. Jirasukprasert, P.; Garza-Reyes, J.A.; Kumar, V.; Lim, M.K. A Six Sigma and DMAIC application for the reduction of defects in a rubber gloves manufacturing process. Int. J. Lean Six Sigma 2014, 5, 2-21. [CrossRef]

9. McIntosh, R.I.; Culley, S.J.; Mileham, A.R.; Owen, G.W. A critical evaluation of Shingo's ,SMED' (Single Minute Exchange of Die) methodology. Int. J. Prod. Res. 2010, 38, 2377-2395. [CrossRef]

10. Ram, K.; Kumar, S.; Singh, D.P. Industrial benefits from a SMED methodology on high speed press in a punching machine: A review. Adv. Appl. Sci. Res. 2015, 38-41.

11. Rahman, S.; Laosirihongthong, T.; Sohal, A.S. Impact of lean strategy on operational performance: A study of Thai manufacturing companies. J. Manuf. Technol. Manag. 2010, 21, 839-852. [CrossRef]

12. Haleem, R.M.; Salem, M.Y.; Fatahallah, F.A.; Abdelfattah, L.E. Quality in the pharmaceutical industry-A literature review. Saudi Pharm. J. 2015, 23, 463-469. [CrossRef] [PubMed] 
13. Faccio, M.; Cohen, Y.; Bevilacqua, M.; Ciarapica, F.E.; De Sanctis, I.; Mazzuto, G.; Paciarotti, C. A Changeover Time Reduction through an integration of lean practices: A case study from pharmaceutical sector. Assembly Autom. 2015, 35, 22-34.

14. Kumar, B.S.; Abuthakeer, S.S. Implementation of lean tools and techniques in an automotive industry. J. Appl. Sci. 2012, 12, 1032-1037. [CrossRef]

15. Kesterson, R.K. The Intersection of Change Management and Lean Six Sigma; CRC Press: Boca Raton, FL, USA, 2018; pp. 3-50.

16. Al-Akel, K.; Marian, L.; Harea, C. Analysis of Global Japanese Management Methods. Use and Efficacy. RMEE. Review of Management and Economic Engineering. No. 5. Ulrich's Periodicals Directory. 2018. Available online: http://www.rmee.org/abstracturi/67/11_studii_si_cercetari_Articol_406_Karam\% 20Al-Akel\%20-\%20RMEE\%202018\%20\%20ANALIZAREA\%20EFICACITATII\%20GLOBALE\%20A\% 20METODELOR\%20JAPONEZE\%20DE\%20MANAGEMENT.pdf (accessed on 23 December 2019).

17. Al-Akel, K.; Marian, L.; Veres (Harea), C.; Gavrilaș, V. DMAIC importance and effectiveness in continuous improvement mindset. In Proceedings of the Review of Management and Economic Engineering, Cluj-Napoca, Romania, 20-21 September 2018.

18. Al-Akel, K.; Marian, L.; Veres (Harea), C.; Horea, R. The contribution of Lean Manufacturing tools to Changeover time decrease in the pharmaceutical industry. A SMED project. Proc. Manuf. J. 2018, 22, 886-892.

19. Shingo, S. A Revolution in Manufacturing: The SMED System; Productivity Press: Stanford, CA, USA, 1985.

20. Cakmakci, M. Process improvement: Performance analysis of the setup time reduction-SMED in the automobile industry. Int. J. Adv. Manuf. Technol. 2009, 41, 168-179. [CrossRef]

21. Ulutas, B. An application of SMED Methodology. World Acad. Sci. Eng. Technol. 2011, 79, 101.

22. Perinić, M.; Ikonić, M.; Maričić, S. Die Casting Process Assessment Using Single Minute Exchange of Dies (SMED) Method. Metalurgija 2009, 48, 199-202.

23. Dave, Y.; Sohani, N. Single Minute Exchange of Dies: Literature Review. Int. J. Lean Think. 2012, 3, 27-37.

24. Mali, Y.R.; Inamdar, K.H. Changeover Time Reduction Using Smed Technique of Lean Manufacturing. Int. J. Eng. Res. Appl. 2012, 2, 2441-2445.

Publisher's Note: MDPI stays neutral with regard to jurisdictional claims in published maps and institutional affiliations.

(C) 2020 by the authors. Licensee MDPI, Basel, Switzerland. This article is an open access article distributed under the terms and conditions of the Creative Commons Attribution (CC BY) license (http://creativecommons.org/licenses/by/4.0/). 